\title{
IN VITRO ANTIFUNGAL ACTIVITY AND TOTAL PHENOLIC CONTENT OF FERMENTATION EXTRACT OF ENDOPHYTIC FUNGI ISOLATED FROM FICUS ELASTICA DECORA
}

\author{
Asmaa A.A. Abd alla(1), A. F. El-Baz ${ }^{(2)}$ and Yousseria M. Hassan ${ }^{(3)}$ \\ (1) Monoufia Univ. hospital, \\ (2) Genetic engineering and biotechnology research institute, University of Sadat city Univ., \\ (3) Faculty of science, Ain Shams Univ.
}

Received: Aug. 21, 2017

Accepted: Aug. 30,2017

\begin{abstract}
The aim of this study was to identify the endophytic fungi isolated from Ficus elastica decora and to investigate their potential antifungal activity and their total phenolic content of their fermentation extract. Two fungal species of endophytic fungi were successfully isolated from leaves including Aspergillus parasiticus and penicillium verrocusom. The fungal extracts were assessed for antifungal activity against Candida albicans where penicillium verrocusom extract showed larger inhibition zone than Aspergillus parasiticus one while Aspergillus parasiricus extract had higher total phenolic content than Penicillium verrocusum one.
\end{abstract}

Key words: Endophytes- Ficus elastica decora-antifungal-total phenolic content.

\section{INTRODUCTION}

Endophytes are microorganisms that are present in living tissue of various plants (root, fruit, stem, seed, leaf etc.) establishing mutual relationship without apparently any symptom of diseases, Sandhu et al. (2014). The endophytic fungi play important physiological and ecological roles in their host life. Recent investigations have been intensified by the potentialities of endophytic fungal strains in production of bioactive metabolites like taxol, pestaloside, torreyanic acid and enzymes, i.e: Xylanase, Isoflavonoids, Asparaginase, Theantana et al. (2007). Medicinal plants are known to harbor endophytic fungi that are believed to be associated with the production of pharmaceutical products, Zhang et al. (2006). Therefore, it is important to explore endophytic mycoflora in the medicinal plants. The present study was carried out to isolate, identify and test antifungal activity and total phenolic content of extracts of endophytic fungi which were isolated from Ficus elastic decora which belongs to the family Moraceae commonly known as the rubber bush, rubber tree, rubber plant, or Indian rubber bush, native to northeast India and southern Indonesia Kiem PV et al. (2012).

\section{MATERIALS AND METHODS Plant Material}

In the present study fungal species were isolated from leaves of Ficus elastica decora which was collected from different sites of Sadat city (Egypt). Healthy and mature plant was carefully chosen for sampling. The plant parts were brought to the laboratory in sterilized bags and processed within a few hours after sampling.

\section{Isolation of Endophytic Fungi}

Isolation of endophytic fungi from plant parts was done according to the method described by Petrini (1986) with modification. First the plant material was rinsed in tap water to remove the dust and debris then cut into small pieces by a sterilized blade under aseptic conditions. Each sample was surface sterilized by $70 \%$ ethanol for 1 minute 
and after that the samples were rinsed in sterile distilled water for 1 minute and then allowed to surface dry on filter paper. After proper drying 4 pieces of plant parts were inoculated in potato dextrose agar (PDA) plate supplemented with antibiotic (chloramphenicol) and incubated at 28 $\pm 1^{\circ} \mathrm{C}$ for 5 to 7 days. Pure colonies were transferred on PDA slant. The fungal strains in the pure culture were preserved on PDA slant at 4 to $5^{\circ} \mathrm{C}$ with proper labeling and were sub-cultured from time to time.

\section{Morphological Identification of Endophytic Fungi}

The fungi were identified on the basis of morphological characteristics. The colonies appearing on petri plates were sub-cultured into the tube containing potato dextrose agar medium for identification. Fungi were again cultured from slant to petri plates containing potato dextrose agar medium without antibiotic (chloramphenicol) for 7 days. Morphological identification was done according to the standard taxonomic key included colony diameter, texture, color and the dimensions and morphology of hyphae and conidia.

\section{Production of Secondary Metabolites}

$100 \mathrm{ml}$ of Potato Dextrose Broth was prepared in $250 \mathrm{ml}$ flasks and autoclaved at $15 \mathrm{lbs}$ psi for $20 \mathrm{~min}$. The medium was inoculated with fungal discs of solid culture and incubated at $28 \pm 1^{\circ} \mathrm{C}$ in the shaker incubator at 120 rpm. After 10 days of incubation the crude culture broth was collected.

\section{Extraction:}

The whole broth was then extracted with equal volumes of ethyl acetate on shaker for 24 hours then the ethyl acetate layer was separated after centrifugation, evaporated using rotatory evaporator and the resulting residue is dissolved in dimethyl sulfoxide (DMSO).

\section{Microbial}

testing:

Tested organisms: Candida albicans :

Stock culture of the tested organism was obtained from the microbiological lab at Faculty of Medicine in Mansoura University.

\section{Filter paper disc assay:}

The antifungal activity of the fungal extracts were estimated by filter paper disc method (Murray et al., 1998) using inoculums containing $10^{6}$ fungal cells I $\mathrm{ml}$ to spread on nutrient agar plates.

The sterilised filter paper discs (Whatman no.1, $6 \mathrm{~mm}$ in diameter) were saturated with the tested extracts. The discs were placed on the surface of agar plates seeded with the test organism. The plates were incubated at $30^{\circ} \mathrm{C}$. Diameters of inhibition zone $(\mathrm{mm})$ were measured after 24-36 hours, Sardari et al., (1998).

\section{Total phenolic compounds content:}

The total phenolics content of fungal extracts was measured using the modified Folin Ciocalteu colorimetric assay developed by Wolfe et al., (2003).

A known volume $(1 \mathrm{ml})$ of plant extract or standard solutions of gallic acid was added $10 \% 5 \mathrm{ml}$ of Folin Ciocaltu reagent. After 3 minutes, $4 \mathrm{ml}$ of sodium carbonate (75 g/L) was added and the mixture allowed to stand for 30 minutes at $40^{\circ} \mathrm{C}$ to the exclusion of light. The absorbance was measured at $765 \mathrm{~nm}$.

\section{RESULTS}

Isolation and identification of endophytic fungi: 
In the present study, fungal strains were isolated from the leaves of Ficus elastica decora. A total of 2 fungi were isolated which belong to Ascmycetes. Identification of these fungal strains was done on the basis of their cultural and microscopic properties. These fungi were successfully identified as Aspergillus parasiticus and penicillium verrocusom.

\section{Screening of endophytic fungi for antifungal activity:}

Screening of endophytic fungi to determine the antifungal activity was done against Candida albicans. Penicillium verrocusom provided zone of inhibition equals $(9 \mathrm{~mm})$ and Aspergillus parasiticus(8mm).

\section{Total phenolic content:}

In present study, 2 fungal extracts were investigated for total phenolic contents by using the modified Folin Ciocalteu colorimetric assay. The total phenolics content of penicillium verrocusom was $(3.765 \mathrm{mg} / \mathrm{ml})$ and Aspergillus parasiticus was $\quad 6.135$ $\mathrm{mg} / \mathrm{ml})$.

\section{Discussion:}

The antifungal activity of endophytic fungal extracts was proven in other studies as Colletotric acid, a metabolite of Colletotrichum gloeosporioides, an endophytic fungus from the plant Artemisia mongolica, displayed antimicrobial activity against bacteria as well as against fungus, Helminthosporium sativum, Zou et al. (2000). In another study Colletotrichum sp. isolated from Artemisia annua, produces bioactive metabolites that showed varied antibacterial and antifungal activity, Hong et al. (2000). For Penicillium citrinum; Wen et al. (2014) have proven the production of a novel antifungal protein by Penicillium citrinum $W 1$, which was isolated from a
Southwest Indian Ocean sediment sample, purified and characterized. The culture supernatant of $P$. citrinum $W 1$ inhibited the mycelial growth of some plant pathogenic fungi.

Phenols and terpenes are the main chemical constituents responsible forreducing lipid peroxidation and hence act as primary and secondary antioxidants Gulcin,(2006). In this study, extracts having high phenolic content also showed good antioxidant activity. Previous studies conclude that there is a linear correlation between total phenolic content and antioxidant potential of any sample, Sultana et al. (2007).

\section{REFERENCES}

Gulcin, I. (2006). Antioxidant and antiradical activities of L-carnitine. Life Sci; 78(8): 803-811.

Hong, L.u., X. Z. Wen, C. M. Jun, H. Jun and X. T. Ren (2000). New bioactive metabolites produced by Colletotrichum sp., an fungus in Artemisia annua. Plant Sci ; 151:6773.

Kiem, P.V., V. M. Chau, X. N. Nguyen, T.T. Huu, Hong, Q.; Hoang, L. T. A.; Nguyen, X. C.;Truong, N. Ha.;Seung, $H$. K.;Jin, K. K.;Hae-Dong, J.and Young, H. K.(2012).Chemical constituents of the Ficus elastica leaves and their antioxidant activities. Bulletin of Korean Chemical Society. 33(10); 3461-3464.

Murray, R., S. Rosenthal, S. Kobayashi and A. Pfaller (1998). Medical Microbiology. 3rd ed. St. Louis: Mosby.p.161.

Petrini, O. (1986). Taxonomy of endophytic fungi of aerial plant tissues. In: Microbiology of the phylosphere; pp175-187.

Sandhu, S.S., K. Suneel, R.P. Aharwal, H. Shukla and R.C. Rajak (2014). Endophytic Fungi: As A Source of Antimicrobials Bioactive Compounds. 
Asmaa A.A. Abd alla, et al.,

World J Phar Pharmac. Wen, C., G. Wenbin and C. Xinhua Sci.;3(2):1179-1197.

(2014). Purification and Identification of a Novel Antifungal Protein Sardari, A., M. Gholamreza and M. Daneshtalab

Phytopharmaceuticals. Part 1: Antifungal Activity of Selected Iranian and Canadian Plants. Pharm. Biol.; (36):180-188.

Sultana, B., F. Anwar, R. Przybylski, Antioxidant activity of phenolic components present in barks of Azadirachta indica, Terminalia arjuna, and Eugenia jambolana Lam. trees. Food Chem 2007; 104(3): 1106-1114. Secreted by Penicillium citrinum from the Southwest Indian Ocean. J. Microbiol. Biotechnol.; 24(10). 13371345.

Wolfe, K., X. Wu and R. Liu (2003). Antioxidant activity of apple peels. J. Agric. Food Chem.; 51: 609-614.

Zhang, H.W., Y.C. Song and R.X. Tan (2006). Biology and chemistry of endophytes. Nat Pro Rep.;23:753.

Zou, W.X., J.C. Meng, H. Lu, G.X. Chen, G.X. Shi and T.Y. Zhang (2000). Metabolites of Colletotrichum gloeosporioides, an endophytic fungus in Artemisia mongolica. J Nat Prod; 63: 1529-1530. isolated from some Thai medicinal plants. KMITL Sci Tech J.;(S1):1318.

\title{
النشاط المضاد للفطريات والمحتوي الفينولي لمستخلص التخمر للفطريات المعزولة

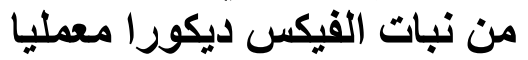

\author{
أسماء عادل عبدالله(1) ، أشرف فرج الباز (2) ، يسرية محمد حسن(3)

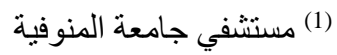 \\ (2) معهد بحوث الهندسة الور اثية و التكنولوجيا الحيوية

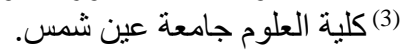




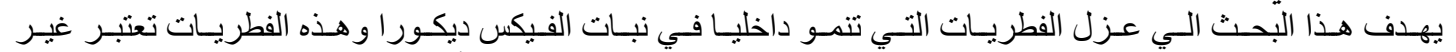

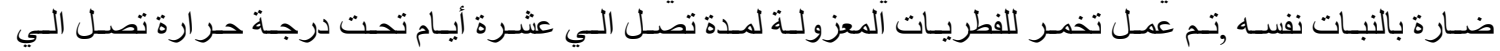

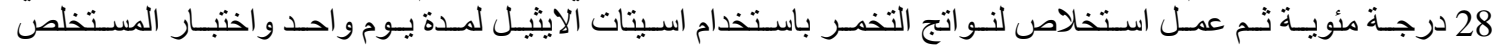

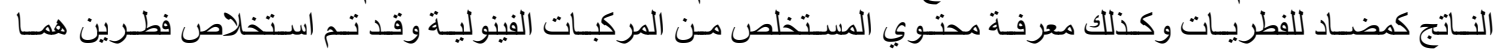

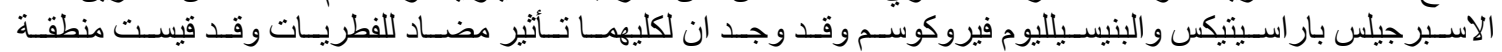

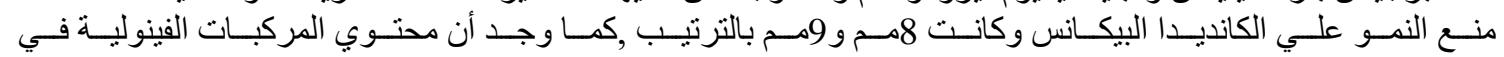
مستخلص الفطرين 6,135 و3,765 مجم/ملل بالترنيب. 